International Journal of Scholarly Papers for Media and Communications

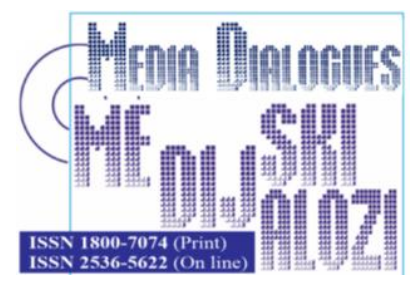

Shilina, M., Delibasic, M. (2021), „Data Journalism as a New Type of Media Communication", Media Dialogues / Medijski dijalozi, Vol. 14, No. 3, pp. 7-13.

\title{
Data Journalism as a New Type of Media Communication
}

\author{
Professor MARINA G. SHILINA, \\ National Research University - Higher School of Economics, \\ Moscow, Russia
}

Assistant Professor MILICA DELIBASIC,

Mediterranean University, Faculty of Business Studies,

Podgorica, Montenegro

\begin{tabular}{|c|c|}
\hline $\boldsymbol{A} \boldsymbol{R} \boldsymbol{T} \boldsymbol{I C L} \boldsymbol{E}$ & Received: March 17, 2021 / Revised from: April 19, 2020 \\
$\boldsymbol{I N F \boldsymbol { O }}$ & Accepted: May 19,2021 / Available online: January 15, 2021 \\
\hline DOI & doi.org/10.14254/1800-7074/14-1/1 \\
\hline
\end{tabular}

\begin{abstract}
What influence professional indtity of journalist? The answer in not easy. We regard this identity as a composition of various journalistic ide-als, such as objectivity, neutrality and scrutiny. But these ideals changes over time. Media relations to both economic and political forces have changed, and the increasing commercialization of news work has been paral- leled by a racing technological development and changes of the journalist corps structure. All these changes together constitute the field, staging the particular shape of professional identity that dis-
\end{abstract}


tinguishes journalists. This paper will analyze influence of the above listed forces on shaping of profes- sional indentify with a particular attention technological development and changes

KEYWORDS: Mass media, communication, the internet, database, data journalism, integration, open governance

\section{INTRODUCTION}

In the 2010-th theoreticians and practitioners of mass media are searching new optimal economic and creative models of media. Experts (UNESCO, 2011) have identified a number of trends that could "grow" in practices of media next five or ten years, such as new technologies, new screens and portals for information delivery, increasing participation of prosumers based on creativity and self-expression, and the rise of using of game technologies in the discourse as well. Thus, the main features of media information and communica- tion based on new technologies are interactive creative formats.

In Russia the media system has changed profoundly over recent decades market influence, and the consequences have been similar to those in foreign media: „a restructuring of the media system, quantitative growth, increased diversity in media channels and media content, regionalization of the media markets, and the introduction of ICT into the media infrastructure and into the media system itself" (Vartanova, 2013). So, the trends of development of Russian media could be similar to those in world industry.

Digitalization, convergence and the Internet have constructed the features of the new models of communication for media professionals and audiences.

The most important feature of the communication in the Internet is hypertext, which determines the basic properties of technical, technological and social, humancentered levels of interaction in this space. The main characteristic of the Internet is hypertext, it provides through hyperlinks and multimedia a synergy of two opposite processing formats of communication such as logical and associative and also provides subject-to-subject interactivity. Other characteristics such as openness, non-limited access to information and communication, and enhanced speed of information distribution are sure to contribute.

In fact in the Internet due to those characteristics any content can be characterized as media content, a priori available for reading and changes by the audiences.

Media sector of Russian Internet is one of the most rapidly developing fields of professional information and communication. But there are digital divide factors which include the lack of broadband access to the Internet all over the territory of 
the country, the low technical culture of society as well as rather high prices for Internet services, etc.

M. Lukina also mentioned that "the development of the sector is also limited because of the lack of legal base in the field, the lack of respect to copyrighting, and poor personal data protection mechanisms". And concluded: "However, despite the objective difficulties the dynamics of Internet usage in Russia is growing positively and contributes to consumers' demand for online information. This fact encourages renovation processes in Russian digital media" (Lukina, 2013).

\section{DATA JOURNALISM: FEATURES \& FUNCTIONS}

Digitalization has changed media and journalism profoundly. In the 1950s due to electronic computer information the concept of use and presentation of information in journalism, primarily the U.S., has changed. The distinctive feature of the socalled computer-assisted reporting was the systematic using of computer and digital information, facts, statistics, studies, and the analysis of data bases to enhance the quality of content, strengthen the evidence base, especially in the investigations.

Among the essential characteristics of digitization are so-called open data (big data) bases of digital information.

The term "data" describes large volumes of digital computer information, but in the humanities, from the communicative point of view the database definition was not given. In this paper we use a definition based on the interpretation of Article 1280 of the Civil Code of the Russian Federation and a number of definitions of communication: the database is presented in the form of an objective set of materials (statistics, articles, etc.), systematized in such a way that the data materials can be found and processed digitally by audience.

Today the term is used to refer to various types of data bases, including the important social computer data that can be stored in the public domain, used free by the mass audience.

Data base is open and free used, so the main aims of journalist working with data are connected with methods of analysis, interpretation and presentation of content.

Data journalism as a kind of professional communication and creation of a converged media content based on the use of large amounts of computer and Internet data was born in the first decade of this century.

Foreign and Russian practices of data journalism are in the process of formation, but the main features are determined by ICT, and it's possible to analyze this phenomenon from the theoretical point of view correctly. 
The traditional (non digital) data and fact are the foundation of journalism, the appointment of the facts in the journalistic content is multifunctional: data can be the basis of the information message, can act as arguments and scientific evidence.

The examples of using the different types of data to create more effective journalistic text some scientists date back to the first third of the 21th century. In particular, Simon Rogers describes the article in the British newspaper "The Guardian" (1821), where a list of schools of Manchester with the number of pupils of different categories analyzed, as the first example of data journalism.

This example is not quite correct, as the term „data“ in respect of journalism refers primarily to computer data, Internet data communications network, which have specific properties, briefly indicated above.

The protoforms of the phenomenon of today's "data journalism" are the latest journalistic practices of using computer equipment and digital and Internet technologies for analysis and presentation of journalist information in various media sources.

The term "data journalism" was defined in 2006 by one of the first American data journalists Adrian Holovaty as outlined structured, machine-readable data, used by a journalist with traditional media text .

At present, such definition is not quite correct, because data journalists use not only a computer and Internet communication, but many new different types of convergence content, which become more and more diverse.

The specificity of data communication is that the authors use the digital data not as a tool for creating text or photo, picture, infographic series for it, but as a major source of formation of topics, concepts, as a key condition for choosing the genre. Implementation of this online format means the use of converged multimedia hypertext type of message as a new type and method of media communication in every media model: the data and the author, the author and the text / content, the data and the audience, the audience and the text / content, the audience and the author, etc.

Various patterns of data communication and journalism, and online journalism, noted above, are different from the classical analytical journalism types of text as report, correspondence, interview, survey, discussion, comment, reply, profile, sociological summary, review, article, version, experiment, epistle, an essay, a recommendation.

The typical example of data journalism is data blog of "The Guardian" (Guardian Datablog, launched in 2009 by Simon Rogers). Today at least five journalists write to the blog several times a day, which illustrates the increasing demand on such information.

The practices of BBC and NYT demonstrates that data journalism becomes more and more popular. 
In Russia examples of data journalism are rather rare. The best example is the project "Accidents with pedestrians in Novosibirsk", started in 2011, which won the first prize of Data Journalism Awards-2012, organized by the Global Editors Network. Journalists and citizens of Novosibirsk collect and analyze the data of the local traffic police and hardware resource that provides information about the most dangerous for pedestrians streets of Novosibirsk for a year.

What are the main features of data communication model? They are formed at all stages of the process. For the subject it's finding the threads of information, analysis using the software MySQL, Python, etc., visualization and original presentation of statistic data in the form of journalistic story (or as an equal part of the plot). The journalist must be a good analyst, and writer, and user of technical tools for data visualization (f.e. Google Docs, IBM ManyEyes, Excel, etc.). Thus, data journalist should possess the features of two different types of thinking: logical and associative, and two types if communication: on-line virtual and off-line real, Also web-designer and web-programmer are the subjects of data-communication model.

The most important point of data journalism is interactive and personal involvement of audience in the process of communication. F.e. "Financial Times" offers the reader an interactive form of personal budget connected with the global financial trends, or the overall level of national unemployment rate for a particular family, etc.

Data communication audience could take part in communication, so, the prosumers might to have skills and tools rather equal to journalist.

Journalist Sarah Slobin ("The Wall Street Journal") gives simple, understandable to the reader, personally oriented and effective example on data journalism, realized by "The Las Vegas Sun". Journalists published several articles about health care, prepared on the analysis of 2.9 million hospital records, invoices from public sources, which are allowed to disclose the 3600 injuries, infections and surgical errors that could have been prevented. The interactive graph, identifying problems of all hospitals, gave the readers opportunity to view information, specific to each of them, and then choose the best hospital for themselves.

Thus, data, both computer and net, is not only a source of information for journalists, the original tool for creating a new type of content and communication, but it's a basis for all journalistic classic genres, from news up to investigation in all types of digital media.

Also the data bases are widely used as a source of information for the development of innovative processes, and in March 2013 the European Institute of Innovation and Technology (EIT) conducts a large-scale international conference "Datainnovation: the new imperative of growth".

And, of course, the potential damage from the incomplete disclosure of information, error in the analysis of large data sets, especially in the forward-looking research, of course, is potentially great, and this damage increases the responsibility 
of the analyst, etc. Another problem, despite the obvious potential of big data, is a growing amount of private personal data, and disclosure, that may violate the rights of readers. Also, there are many technical problems, in particular most of the data generated now, is unstructured and casually organized, this cannot affect the validity of the analysis.

\section{CONCLUSION}

The study of the first data practices of journalism as a phenomenon and process allow us to formulate a working definition: data journalism is a set of specific skills to search, analyze, visualize data information from digital sources for the construction of a unique interactive analytical content for effective interaction with the audience; the method of its creation, transmission, consumption, which can be used as meta-method and meta-base for other journalistic genres.

From a theoretical point of view the paper fixes a new format of the integration of different approaches of using of facts as the main category of journalism and the possibility of synthesis, and synergy of all journalistic genres. This type of content and communication is new to journalism but it seems a logical continuation of convergent trends of development of mass media.

These qualitative changes in media communication makes relevant the concept of an integrated theory of media (medialogy) based on a digital media communication, offered by the author.

From the point of view of professional journalism, construction of data communication strengthens human, rather than technocratic trends in media communication, because the creation of original journalistic content based on open standard statistical materials requires the specific interpretation and the choice of digital form.

The emergence of data as a new type of factual information and media communication, displays journalism to a new level of functioning in society.

The transition from the concept of "genre" to the phenomenon of media content, and communication process corresponds to the dialectical nature of social communication, which is both a function of society and its institution, the backbone element and the product of it.

Data journalism communication can be defined as social integrated communication, because of its influence on social processes.

Not in summary but in clarification let's note that data journalism corresponds the government programs of open governance, around the world and in Russia, which contribute to the development of this type of data bases, and, consequently, to data journalism as a new and significant driver of social development. 


\section{REFERENCES}

Dennis, E., Rivers, W. (1974), Other Voices. The New Journalism in America, N.Y. Lukina, M (2013), „Russian Media and the Internet“, World of MediaYearbook of Russian Media and Journalism Studies 2012, pp. 192 - 193.

Vartanova, E. (2013), „Constructing Russian Media System in the Context of Globalization", World of MediaYearbook of Russian Media and Journalism Studies 2012, pp. 32-33.

UNESCO (2011), Future arts, media, and entertainment: seeds for 2020, N.Y. 